\title{
Stability Research on Boundary Values of Quasilinear Elliptic
}

\section{Equation}

\section{Chunxia Gao}

\author{
Hebei University, Baoding, 071002, China
}

\begin{abstract}
In recent years, the research on partial differential equation attracts more and more scholars' attention; the quasilinear elliptic equation is an important part of partial differential equation field, and the stability research on boundary values of quasilinear elliptic equation can be established on the basis of existence and uniqueness. Through appropriate research and discussion on existence and uniqueness of boundary values of quasilinear elliptic equation, this paper carries out a research on stability of boundary values of quasilinear elliptic equation under condition of region, $P$ value, and capacity, etc.
\end{abstract}

Key words: quasilinear elliptic equation; boundary values of equation; stability

With the progress of the era and social development, more and more scholars expand the research on partial differential equation, especially research on quasilinear elliptic equation. Because the quasilinear elliptic equation is an important part of partial differential equation field, it is closely related with medical science, economics, industry, biology, and engineering science, and it is often applied in information science, physics, and other disciplines and fields. As for quasilinear elliptic equation, the stability of boundary values is established on the existence and uniqueness of boundary values, thus this paper carries out an appropriate research on stability of quasilinear elliptic equation under the condition of region, and index P, etc.

\section{Existence and uniqueness of boundary values of quasilinear elliptic equation}

In order to carry out research and discussion on existence and uniqueness of boundary values of quasilinear elliptic equation, we firstly make use of and have the aid of the theorem of implicit function to discuss the following (1.1) equation set formulas for the purpose of proving that the boundary values of quasilinear elliptic equation have 
continuous dependence and further proving the existence and uniqueness of boundary values of quasilinear elliptic equation.

$$
\left\{\begin{array}{l}
\left(\mathrm{r}^{\mathrm{n}-1} H\left(\mathrm{u}^{\prime}(\mathrm{r})\right)\right)^{\prime}+\mathrm{r}^{\mathrm{n}-1} \mathrm{f}(\mathrm{r}, \quad(\mathrm{r}(\mathrm{r})))=0, \mathrm{r} \geq 0 \\
\mathrm{u}(\mathrm{r})\rangle 0, \quad \mathrm{r} \geq 0 \\
\mathrm{u}(0)=\alpha>0, \mathrm{u}^{\prime}(0)=0
\end{array}\right.
$$

According to the formula (1.1), it is able to obtain the equation $\mathrm{u}(\mathrm{r})=\alpha-\int_{0}^{\mathrm{r}} H^{-1}\left(\int_{0}^{\mathrm{r}} \frac{\sigma}{\mathrm{s}}\right)^{\mathrm{n}-1} \int(\sigma, \mathrm{u}(\sigma)) \mathrm{ds}(1.2)$, thus it is able to carry out the research on existence and uniqueness via the equation in formula (1.2), wherein $\mathrm{H}(\mathrm{t})$ and $\mathrm{f}(\mathrm{x}$, u) are set to meet following conditions:

1. $\mathrm{f}:[0, \infty) \times(0, \infty) \rightarrow(0, \infty)$ is continuous;

2. $H^{-1}(\mathrm{t})$ is continuous and differentiable, and $\mathrm{f}$ is first-order continuous and partial;

3. $H(0)=H^{-1}(0)=0$;

4. Upon $\mathrm{u}>0$, $\mathrm{f}(\mathrm{x}, \mathrm{u})$ has consistent local continuity;

5. $H^{-1}(\mathrm{t})$ has local continuity;

6. $\mathrm{H}(\mathrm{t})$ belongs to strict increase;

7. In $\mathrm{f}(\mathrm{t}, \mathrm{s})$, $\mathrm{t}$ is strictly monotonic decreasing for $\mathrm{s}$.

Theorem 1: Given that the condition 1-5 are satisfied, it is able to obtain the local solution in existence and uniqueness of equation (1.2) as $\mathrm{u}(\mathrm{r}, \mathrm{a})$ and $\mathrm{r} \in\left[0, \mathrm{r}_{\alpha}\right]$.

Through using the formula (2) as auxiliary function, it is able to obtain following equation:

$$
F(\mathrm{r}, \mathrm{u})=\mathrm{u}(r)-\alpha+\int_{0}^{\mathrm{r}} H^{-1}\left(\int_{0}^{\mathrm{r}}\left(\frac{\sigma}{\mathrm{s}}\right)^{\mathrm{n}-1} \mathrm{f}(\sigma, \mathrm{u}(\sigma)) \mathrm{d} \sigma\right) \mathrm{ds}
$$

At this time, given that $\mathrm{r}_{0}=0, \mathrm{u}_{0}=\alpha$, and the point $\mathrm{p}_{0}(\alpha, \beta)$, it is able to find that the following results can be established.

1. $\mathrm{F}(\mathrm{r}, \mathrm{u})$ is continuous within region $\mathrm{U}$ on one domain of the point $\mathrm{p}_{0}$;

2. $\mathrm{F}\left(\mathrm{p}_{0}\right)=0$;

3. Within region $\mathrm{U}, \mathrm{F}$ is first-order continuous and partial function;

4. $F_{\mathrm{u}}(0, \alpha)=1 \neq 0$ 
According to the theorem of implicit function, it is able to find that the unique definition can be determined in formula (2), that is, the implicit function contained in the region of domain $U\left(r_{0}\right)$ in one region upon $r_{0}=0$, thus we can find that the solution of equation set (1) is positively local, that is to say, we can obtain as below:

$\mathrm{u}(\mathrm{r}, \alpha) \in C\left(0, \mathrm{r}_{\alpha}\right) \cap\left[0, \mathrm{r}_{\alpha}\right]$ : through calculation with Gronwall inequation, it is able to obtain $\mathrm{u}_{1}(\mathrm{r})=\mathrm{u}_{2}(\mathrm{r}), \mathrm{r} €\left[0, \mathrm{r}_{0}\right]$, thus we can find that the positive local solution of formula (2) has existence and uniqueness.

Theorem 2: Given that the condition 1, 3, 4, 6, and 7 are satisfied, both $\alpha$ and $\beta$ are positive constant, and $\alpha>\beta$, it is able to obtain $0>\mathrm{u}_{\alpha}{ }_{\alpha}>\mathrm{u}^{\prime}{ }_{\beta}, \mathrm{u}_{\alpha}>\mathrm{u}_{\beta}, \mathrm{r} \in\left[0, \mathrm{R}_{\beta}\right], \mathrm{R}_{\alpha} \geq \mathrm{R}_{\beta}$. Because $\mathrm{f}(\mathrm{r}, \mathrm{u})$ belongs to positive function, it is able to obtain:

$$
H\left(\mathrm{u}_{\alpha}(\mathrm{r})\right)=-\int_{0}^{\mathrm{r}}\left(\frac{\sigma}{\mathrm{r}}\right)^{\mathrm{n}-1} \mathrm{f}\left(\sigma, \mathrm{u}_{\alpha}\right) \mathrm{d} \sigma\langle 0,
$$

Through condition 3 and 6 , it is able to obtain $\mathrm{u}_{\alpha}{ }_{\alpha}$ (r) $<0$, and also obtain $\mathrm{u}_{\beta}{ }_{\beta}$ (r) $<0$.

\section{Stability of boundary values of quasilinear elliptic equation}

2.1 Stability of weak-solution boundary values within region of quasilinear elliptic equation

Through discussion and research on the quasilinear elliptic equation $\left\{\begin{array}{l}-\Delta_{\mathrm{p}} \mathrm{u}=\mathrm{a}(\mathrm{x})|\mathrm{u}|^{\mu-2} \mathrm{u}+\lambda|\mathrm{u}|^{\alpha-1}|v|^{\beta+1} \mathrm{u}+\mathrm{f}_{1}(\mathrm{x}) \\ -\Delta_{\mathrm{q}} \mathrm{v}=\mathrm{b}(\mathrm{x})|\mathrm{v}|^{\nu-2} \mathrm{v}+\lambda|\mathrm{u}|^{\alpha-1}|\mathrm{v}|^{\beta-1} \mathrm{v}+\mathrm{f}_{2}(\mathrm{x}) \\ \mathrm{x} \in \Omega\end{array}\right\}$

, it is found that the following boundary value demand shall be met: $\mathrm{u}=\mathrm{gk}(\mathrm{x}), \mathrm{v}=\mathrm{hk}(\mathrm{x}), \mathrm{x} € \partial \Omega$ (2); in formula (2), given that $\mathrm{k}=1,2,3, \ldots \ldots, \Omega \subset \mathrm{N}(\mathrm{N} \geq 3)$ and given that it is a $\partial \Omega$ bounded region with smooth boundary, the (u, v) in equation set in formula (1) belongs to Sobolev space, where $\mathrm{W}^{1, \mathrm{p}}(\Omega) \times \mathrm{W}^{1, \mathrm{q}}(\Omega)$ and $2<\mathrm{p} \leq \mathrm{q}<\mathrm{N}$; the $\mathrm{p}$, q conjugate number of the function $\mathrm{f}_{1}$ (x) $\mathrm{CL}^{\mathrm{p}^{\prime}}(\Omega), \mathrm{f}_{2}(\mathrm{x}) \mathrm{CL}^{\mathrm{q}^{\prime}}(\Omega)$ are expressed as $\mathrm{p}^{\prime}=\frac{\mathrm{p}}{\mathrm{p}-1}, \mathrm{q}^{\prime}=\frac{\mathrm{q}}{\mathrm{q}-1}$ respectively; as for a (x), b (x) $€ \mathrm{~L} \infty(\Omega), 1<\mu<v<\mathrm{p}$, the positive constant shall meet the condition of $\frac{\alpha+1}{\mathrm{p}}+\frac{\beta+1}{\mathrm{q}}=1 ; \lambda$ belongs to a positive parameter.

Meanwhile, given that $\mathrm{L}$ is a positive constant with appropriate size, its boundary 
function (gk $\quad(\mathrm{x}), \quad$ hk $\quad(\mathrm{x}))$ must meet following conditions: $\left(\mathrm{g}_{\mathrm{k}}(\mathrm{x}), \mathrm{h}_{\mathrm{k}}(\mathrm{x}) \in W^{1-\frac{1}{P}, P}(\partial \Omega) \times W^{1-\frac{1}{\mathrm{q}}, \mathrm{q}}(\partial \Omega)\right.$, and $\|(\mathrm{gk}(\mathrm{x}), \mathrm{hk}(\mathrm{x}))\| \leq \mathrm{L} \cdot \mathrm{W}^{1, \mathrm{p}}(\Omega)$. According to space embedding theorem, $\mathrm{K}_{1}$ is constant, thus $\|\mathrm{u}\|_{\mathrm{p}} \leq \mathrm{K}_{1}\|\mathrm{u}\|_{1}$, $\mathrm{p}$ as for any $\mathrm{uCW}^{1, \mathrm{p}}(\Omega)$. According to same principle, it is able to obtain embedding $\mathrm{W}^{1, \mathrm{p}}(\Omega) \subset \mathrm{L}^{\mathrm{q}}$ $(\Omega)$, and then obtain the best constant $\mathrm{K}_{2}$.

$\mathrm{T}_{1}$ and $\mathrm{T}_{2}$ are set as the continuous mapping produced from $W^{1-\frac{1}{P}, P}(\partial \Omega)$, $W^{1-\frac{1}{\mathrm{q}}, \mathrm{q}}(\partial \Omega)$ to $\mathrm{W}^{1, \mathrm{p}}(\Omega)$ and $\mathrm{W}^{1, \mathrm{q}}(\Omega)$ to make the boundary function $\mathrm{g}$ and h locate on the trace and realize $\left.\mathrm{T}_{1} \mathrm{~g}\right|_{\partial \Omega}=\mathrm{g}$ and $\left.\mathrm{T}_{2} \mathrm{~h}\right|_{\partial \Omega}=\mathrm{h}$. Furthermore, there are 2 positive constants $\mathrm{M}_{1}$ and $\mathrm{M}_{2}$; under the condition of $\left(\mathrm{T}_{1} \mathrm{~g}, \mathrm{~T}_{2} \mathrm{~h}\right) \in \mathrm{W}^{1, \mathrm{p}}(\Omega) \times \mathrm{W}^{1, \mathrm{q}}(\Omega)$, and $\left\|\mathrm{T}_{1} \mathrm{~g}\right\| \leq \mathrm{M}_{1}\|\mathrm{~g}\|,\left\|\mathrm{T}_{2} \mathrm{~h}\right\| \leq \mathrm{M}_{2}\|\mathrm{~h}\|$, with the help of mapping mode, it is able to obtain $\mathrm{u}=\mathrm{y}+\mathrm{T}_{1} \mathrm{~g}_{\mathrm{k}}, \mathrm{v}=\mathrm{z}+\mathrm{T}_{2} \mathrm{~h}_{\mathrm{k}}$, thus it is able to transform formula (1) and (2) into homogeneous boundary value problem, and then carry out definition solution for variation structure on equation set and energy generic function of $W_{0}^{1, \mathrm{p}}(\Omega) \times W_{0}^{1, \mathrm{q}}(\Omega)$ on the space, that is, meeting the critical point of formula (3) shown as below:

$$
\begin{gathered}
I(\mathrm{y}, \mathrm{z})=\frac{\alpha+1}{\mathrm{p}} \int\left|\nabla_{\mathrm{y}}+\nabla T_{1} \mathrm{~g}_{\mathrm{k}}\right|^{\mathrm{p}} \mathrm{dx}+ \\
\frac{\beta+1}{\mathrm{q}} \int\left|\nabla_{\mathrm{z}}+\nabla \mathrm{h}_{\mathrm{k}}\right|^{\mathrm{q}} \mathrm{dx}- \\
\lambda \int\left|\mathrm{y}+\mathrm{T}_{1} \mathrm{~g}_{\mathrm{k}}\right|^{\alpha+1}\left|\mathrm{z}+T_{2} \mathrm{~h}_{\mathrm{k}}\right|^{\beta+1} \mathrm{dx}- \\
\frac{\alpha+1}{\mu} \int \mathrm{a}(\mathrm{x})\left|\mathrm{y}+T_{1} \mathrm{~g}_{\mathrm{k}}\right|^{\mu} \mathrm{dx}- \\
(\alpha+1) \int \mathrm{f}_{1}(\mathrm{x}) \quad\left(\mathrm{y}+T_{1} \mathrm{~g}_{\mathrm{k}}\right) \mathrm{dx}- \\
\frac{\beta+1}{v} \int \mathrm{b}(\mathrm{x})\left|\mathrm{z}+T_{2} \mathrm{~h}_{\mathrm{k}}\right|^{v} \mathrm{dx}- \\
(\beta+1) \int \mathrm{f}_{2}(\mathrm{x}) \quad\left(\mathrm{z}+T_{2} \mathrm{~h}_{\mathrm{k}}\right) \mathrm{dx}
\end{gathered}
$$

It is given that the function $(\mathrm{y}, \mathrm{z})$ of $W_{0}^{1,} \mathrm{p}(\Omega) \times W_{0}^{1, \mathrm{q}}(\Omega)$ in Banach space has zero boundary value, and the norm of function is defined as $\|(y, z)\|=\max \left\{\|y\|_{1, p},\|z\|_{1, q}\right\}$, with $\|\mathbf{u}\|_{1, \mathrm{p}}=\left[\int|\nabla \mathbf{u}|^{\mathrm{p}} \mathrm{dx}\right]^{\frac{1}{\mathrm{p}}}$. 
Then, it is given that $\left(g_{k}, h_{k}\right), k \in N$ is a sequence of function which belongs to trace space; therefore, any for any function set in trace space: $(\phi, \varphi) \in W_{0}^{1, p}(\Omega) \times W_{0}^{1,}{ }^{q}(\Omega)$, it is able to obtain following functional sequence:

$$
\begin{aligned}
& M_{\mathrm{k}}(\mathrm{y}, \mathrm{z}) \quad(\phi, \varphi)= \\
& \int\left|\nabla\left(\mathrm{y}+T_{1} \mathrm{~g}_{\mathrm{k}}\right)\right|^{\mathrm{p}-2} \nabla\left(\mathrm{y}+T_{1} \mathrm{~g}_{\mathrm{k}}\right) \nabla \phi \mathrm{dx}+ \\
& \int\left|\nabla\left(\mathrm{z}+T_{2} \mathrm{~h}_{\mathrm{k}}\right)\right|^{\mathrm{q}-2} \nabla\left(\mathrm{z}+T_{2} \mathrm{~h}_{\mathrm{k}}\right) \nabla \varphi \mathrm{dx} \\
& N_{K}(\mathrm{y}, \mathrm{z}) \quad(\phi, \varphi)= \\
& \int \mathrm{a}(\mathrm{x})\left|\mathrm{y}+T_{1} \mathrm{~g}_{\mathrm{k}}\right|^{\mu-2}\left(\mathrm{y}+T_{1} \mathrm{gk}\right) \phi \mathrm{dx}+ \\
& \int \mathrm{b}(\mathrm{x})\left|\mathrm{z}+T_{2} \mathrm{~h}_{\mathrm{k}}\right|^{\nu-2}\left(\mathrm{z}+T_{2} \mathrm{~h}_{\mathrm{k}}\right) \varphi \mathrm{dx}+ \\
& \lambda \int\left|\mathrm{y}+T_{1} \mathrm{~g}_{\mathrm{k}}\right|^{\alpha-1}\left|\mathrm{z}+T_{2} \mathrm{~h}_{\mathrm{k}}\right|^{\beta+1} \times \\
& \left(\mathrm{y}+T_{1} \mathrm{~g}_{\mathrm{k}}\right) \phi \mathrm{dx}+\lambda \int\left|\mathrm{y}+T_{1} \mathrm{~g}_{\mathrm{k}}\right|^{\alpha+1} \times \\
& \left|\mathrm{z}+T_{2} \mathrm{~h}_{\mathrm{k}}\right|^{\beta-1}\left(\mathrm{z}+T_{1} \mathrm{~h}_{\mathrm{k}}\right) \phi \mathrm{d} \mathrm{x}+ \\
& \int \mathrm{f}_{1}(\mathrm{x}) \phi \mathrm{dx}+\int \mathrm{f}_{2}(\mathrm{x}) \varphi \mathrm{dx}
\end{aligned}
$$

Then, while the generic function I (y, z) belongs to $W_{0}^{1,} \mathrm{p}(\Omega) \times W_{0}^{1, \mathrm{q}}(\Omega)$, all critical points $(\mathrm{y}, \mathrm{z})$ shall meet $M_{\mathrm{k}}(\mathrm{y}, \mathrm{z}) \quad(\phi, \varphi)-N_{\mathrm{k}}(\mathrm{y}, \mathrm{z}) \quad(\phi, \varphi)=0(5)$; in the formula (5), the left end is set as $J_{\mathrm{k}}(\mathrm{y}, \mathrm{z}) \quad(\phi, \varphi)$, and the set of function set $(\mathrm{y}, \mathrm{z})$ set in formula (5) is $U_{k}$, and then the weak-solution set owned by quasilinear elliptic equation set (1) and (2) is $V_{\mathrm{k}}=U_{\mathrm{k}}+\left(T_{1} \mathrm{~g}_{\mathrm{k}}, T_{2} \mathrm{~h}_{\mathrm{k}}\right)$

Through effective connection among formula (1), (2), (3), (4), (5), and (6) in above 3.1, it is able to obtain following theorem conclusions.

Theorem 1: Given that the sequence $\left(g_{k}, z_{k}\right)$ of boundary function can have convergence in trace space, while it is up to $\left(\mathrm{g}_{0}, \mathrm{~h}_{0}\right)$ via strong convergence, the sequence $J_{\mathrm{k}}(\mathrm{y}, \mathrm{z}) \quad(\phi, \varphi)$ produced on $\mathrm{Br}$ will have uniform convergence to $J_{0}(\mathrm{y}, \mathrm{z}) \quad(\phi, \varphi)$.

Theorem 2: In case of any $(\mathrm{y}, \mathrm{z}),(\phi, \varphi) \in B_{\mathrm{r}}$, there will be a uniform convergence for functional sequence $J_{\mathrm{k}}(\mathrm{y}, \mathrm{z}) \quad(\phi, \varphi)$ on $\mathrm{Br}$; while it is up to 
$J_{0}(\mathrm{y}, \mathrm{z})(\phi, \varphi)$ via convergence, the following two points will exist: firstly, as for each $k=1,2,3, \ldots$, the set $U_{k}$ is compact at the significance of norm topology; secondly, the sequence $\left\{\left(\mathrm{y}_{\mathrm{k}}, \mathrm{z}_{\mathrm{k}}\right\}\right.$ which meets $\left(\mathrm{y}_{\mathrm{k}}, \mathrm{z}_{\mathrm{k}}\right) \in U_{\mathrm{k}}, \mathrm{k} \in N$ is compact, that is to say, at the significance of strong topology, $\lim \sup _{\mathrm{k}} \subset \mathrm{U}_{0}$, which means that $U_{\mathrm{k}} \rightarrow U_{0}$ is satisfied.

\subsection{Stability of quasilinear elliptic equation at p index}

Given that $\Omega$ belongs to bounded open set in $\mathrm{R}^{\mathrm{n}}(\mathrm{n}>3)$ region and the boundary it has belongs to consistent p thickness, it is able to obtain according to quasilinear elliptic equation:

$$
\left\{\begin{array}{l}
-\operatorname{div}_{\mathrm{p}}(\mathrm{x}, \mathrm{u}, \quad D \mathrm{u})=\mathrm{f}(\mathrm{x}), \operatorname{in} \Omega \\
\mathrm{u} \in W_{0}^{1-\mathrm{p}}(\Omega), 1<\mathrm{p}\langle\infty
\end{array}\right.
$$

Given that Ap: $\Omega \times R \times R^{\mathrm{n}} \rightarrow R^{\mathrm{n}}$ is a function belongs to Carathédory in $\left(\mathrm{M}_{1}\right)$, as for anys $\in R, \quad \xi \in R^{\mathrm{n}}$, a.e.x $\epsilon \Omega$, it is required to meet $A_{\mathrm{p}}\left(\mathrm{x}, \mathrm{s}, \quad \xi \geq \alpha|\xi|^{\mathrm{p}}, \forall \xi \in R^{\mathrm{n}}\right.$ (2) and $\left|A_{\mathrm{p}}(\mathrm{x}, \mathrm{s}, \xi)\right| \leq \mathrm{b}_{1}(\mathrm{x})+\mathrm{b}_{2}(\mathrm{x})|\mathrm{s}|^{\mathrm{q}}+|\xi|^{\mathrm{p}-1}$ (3); upon $\xi_{1} \neq \xi_{2}$, there will be $\left.\left(A_{\mathrm{p}}\left(\mathrm{x}, \mathrm{s}_{1}, \xi_{1}, \quad\right)-A_{\mathrm{p}}\left(\mathrm{x}, \mathrm{s}_{2}, \xi_{2}\right)\right)\left(\xi_{1}-\xi_{2}\right)\right\rangle 0$; the formula (3) and (4) can change, and $A_{p}$ changes with the change of $p$.

Meanwhile, given that $A \mathrm{i}\left(\mathrm{x}, \mathrm{u}_{\mathrm{i}}, \nabla \mathrm{u}_{\mathrm{i}}\right)=A \mathrm{p}_{\mathrm{i}}\left(\mathrm{x}, \mathrm{u}_{\mathrm{i}}, \nabla \mathrm{u}_{\mathrm{i}}\right)$, the problem way of Dirichlet shall be considered according to equation demand, and then it is able to determine the stability of weak-solution p index on quasilinear elliptic equation set via the equation in formula (5).

$$
\left\{\begin{array}{l}
-\operatorname{div} A_{\mathrm{i}}(\mathrm{x}, \mathrm{u}, \quad D \mathrm{u})=\mathrm{f}(\mathrm{x}), \operatorname{in} \Omega \\
\mathrm{u}_{\mathrm{i}} \in W_{0}^{1-\mathrm{p}}(\Omega), 1<\mathrm{p}_{\mathrm{i}}\langle\infty
\end{array}\right.
$$

Some hypotheses can be made as for $A_{\mathrm{i}}(\mathrm{x}, \mathrm{s}, \xi)$ and $\Omega$ within the region. It is given that $\left(\mathrm{S}_{1}\right)$ is a sequence in $\left(\mathrm{p}_{\mathrm{i}}\right)$, and then we can set $1\left\langle\mathrm{p}_{\mathrm{i}}\left\langle\infty, \mathrm{p}_{\mathrm{i}} \rightarrow \mathrm{p}_{0}\right.\right.$; as for any $\mathrm{i}=0, \quad 1,2, \quad 3, \ldots$, the condition of $\left(\mathrm{M}_{1}\right)\left(\mathrm{p}=\mathrm{p}_{\mathrm{i}}\right)$ shall be met in case of $A_{\mathrm{i}}=A_{\mathrm{pi}}(\mathrm{x}, \mathrm{s}, \xi)$. 
a.e.x $\in \Omega, A_{\mathrm{i}}(\mathrm{x}, \mathrm{s}, \xi) \rightarrow A_{0}(\mathrm{x}, \mathrm{s}, \xi)$ is uniform convergence made by $\mathrm{R}^{\mathrm{n}}$ on a compact subset; besides, it is able to assume $\left(\mathrm{S}_{2}\right)$ as below:

$$
\left.\mathrm{b}_{1}(\mathrm{x}), \mathrm{f}(\mathrm{x}) \in L^{\mu}(\Omega), \mu\right\rangle \frac{\left(\mathrm{n}+\mathrm{p}_{0}\right) \mathrm{p}_{0}}{\mathrm{n}\left(\mathrm{p}_{0}-1\right)}, \mathrm{b}_{2}(\mathrm{x}) \in L^{\infty}(\Omega), 1\left\langle\mathrm { q } \left\langle\mathrm{p}_{\mathrm{i}}-1\right.\right.
$$

However, $\left(\mathrm{S}_{3}\right) \Omega^{\mathrm{e}}$ belongs to consistent $\mathrm{p}$ thickness.

Theorem: If $\left(\mathrm{M}_{1}\right),\left(\mathrm{S}_{1}\right),\left(\mathrm{S}_{2}\right),\left(\mathrm{S}_{3}\right)$ are established, ui $\in W_{0}^{1,} \mathrm{p}_{\mathrm{i}}(\Omega)$ is a weak solution which belongs to formula (5), and then there will be $\mathrm{t}>\mathrm{p}_{0}$; in $W_{0}^{1,}{ }^{\mathrm{t}}(\Omega), \mathrm{u}_{\mathrm{i}}$ is transformed to via norm convergence $\mathrm{u}_{0}$; t tightly depends on $\mathrm{n}, \mathrm{p}_{0}, \alpha, \beta$ and $\mathrm{c}_{0}$.

\section{Stability of opposite boundary values of quasilinear elliptic equation}

The quasilinear elliptic equation is assumed as below:

$\left\{\begin{array}{l}-\Delta_{\mathrm{p}} \mathrm{u}=\lambda Q(\mathrm{x})|u|^{p-2} \mathrm{u}, x \in \Omega, \\ u=g k(x), x \in \partial \Omega, k=0,1,2,3, \ldots \ldots\end{array}\right.$

Upon $\mathrm{p} \geq 2, \mathrm{k}=0,1,2,3, \ldots \ldots$, the weak solution set $U_{\mathrm{k}} \in E \cap L^{\infty}(\Omega)$ obtained via research and discussion on quasilinear elliptic equation (3.1) belongs to set convergence and has certain continuous dependence on boundary value gkEW of quasilinear elliptic equation; in case of $1<\mathrm{p} \leq 2$, there exists the unique weak solution $U_{\mathrm{k}} \in E \cap L^{\infty}(\Omega)$ as for quasilinear elliptic equation (3.1), thus there is certain point convergence function as for stability of boundary values of quasilinear elliptic equation.

While the set $V_{0} \subset E_{0}$ is $\mathrm{V}_{\mathrm{k}}$ on set sequence, under the condition of the upper limit of $\mathrm{k}=1,2,3, \ldots$ and the condition that $\mathrm{yCV}_{0}$ is a lower-limit point of strong topological significance on $\mathrm{E}_{0}$ in the sequence $\{\mathrm{yk}\}$ of function $\mathrm{ykCV}_{\mathrm{k}}(\mathrm{k}=1,2,3, \ldots)$ at any point of $\mathrm{V}_{0}$, the limit on $\mathrm{V}_{\mathrm{k}}$ can be marked as $\lim \sup \mathrm{V}_{\mathrm{k}} \approx \mathrm{V}_{0}$. In other words, the set $U_{k}$ is located in $E_{0}$ and it can be converged into the set $U_{0}$. Given that lim $\sup U_{\mathrm{k}} \subset U_{0}$ is established, it is obvious that the set convergence is equal to point convergence in $\mathrm{E}_{0}$ while $\mathrm{U}_{\mathrm{k}}$ and $\mathrm{U}_{0}$ belong to single-point set.

Given that $g_{k}(k=1,2,3, \ldots)$ belongs to the sequence of a boundary function in $\mathrm{W}$, as 
for any $\varphi \mathrm{CE}_{0}$, it is able to define the functional sequence owned in $E_{0}$ as: $J_{\mathrm{k}}(\mathrm{y})=\left\langle A_{\mathrm{k}}(\mathrm{y}), \phi\right\rangle-\left\langle B_{\mathrm{k}}(\mathrm{y}), \phi\right\rangle$, and then the weak-solution set of quasilinear elliptic equation can be expressed into $U_{\mathrm{k}}=\left\{\mathrm{y} \in E_{0}: \forall \phi \in E_{0}, J_{\mathrm{k}}(\mathrm{y})=0\right\}$. According to relevant theorem, as for any $\mathrm{k} \in \mathrm{N}$, the set $\mathrm{U}_{\mathrm{k}}$ belongs to non-emptiness; then, as for all existing $\mathrm{k}=1,2,3, \ldots$, there will be constant $r>0$ not depending on $\mathrm{k}$ and there will exist $U_{\mathrm{k}} \subset B(\mathrm{r}) \subset E_{0}$.

If $\mathrm{J}_{\mathrm{k}}(\mathrm{y})$ on functional sequence have uniform convergence in $\mathrm{B}(\mathrm{r})$ till $\mathrm{J}_{0}(\mathrm{y})$, the limit set $\lim \sup U_{k}$ owned by $U_{k}$ in solution set sequence belongs to non-emptiness, and such condition is weak closing condition, thus there exists $\lim \sup U_{\mathrm{k}} \subset U_{0}$ under weak topological significance of $\mathrm{E}_{0}$.

Besides, through relevant theorem, it is able to find that there exists $u_{k} \in E$ in at least one solution after the quasilinear elliptic equation (3.1) is used for solution as for any $\mathrm{k} \in \mathrm{N}$, and the obtained solution set belongs to non-emptiness; if $1<\mathrm{p} \leq 2$ appears, it means that $\mathrm{u}_{\mathrm{k}} \mathrm{EE}$ has certain unique existence, that is to say, $\mathrm{U}_{\mathrm{k}}$ belongs to single-point set. Meanwhile, there is constant $\mathrm{R}>0$ and there exists $\mathrm{u}_{\mathrm{k}} \subset B(R)$, and all existing $k=1,2,3, \ldots$ can be met, thus it is able to find that $U_{k}$ in solution set sequence has weak compactness in E. However, if the trace function $g_{k} \rightarrow g_{0}$ has strong convergence in $\mathrm{W}, \quad \mathrm{J}_{\mathrm{k}}(\cdot)$ existing in functional sequence can have uniform convergence in closed $B(r) \subset E_{0}$ till $J_{0}(\cdot)$. In case of $p \geq 2$, according to relevant theorem, it is able to find that there always exists the solution set of $U_{k} \rightarrow U_{0}(k \rightarrow \infty)$ under the condition of E weak topology and strong topology, that is to say, if the weak solution set $U_{k}$ in quasilinear elliptic equation (3.1) is proposed before set convergence, it is able to enhance the stability of opposite boundary value $\mathrm{g}_{\mathrm{k}} \mathrm{EW}$ of quasilinear elliptic equation. In case of $1<\mathrm{p} \leq 2$, the stability of quasilinear elliptic equation is of point convergence significance.

\section{Conclusion}

In a word, as the research and application on partial differential equation attract more and more scholars' attention in recent years, there are also high achievements on this 
aspect. On the basis of research and discussion on existence and uniqueness of boundary values of quasilinear elliptic equation, this paper carries out a research and discussion on stability of boundary values of quasilinear elliptic equation in terms of region and $\mathrm{P}$ value, and proves that the boundary values of quasilinear elliptic equation have continuous dependence at significance of weak and strong convergence, thus ensuring the stability of boundary values of quasilinear elliptic equation.

\section{Acknowledgments}

This paper is a project of Hebei provincial natural science foundation (E2012201088) and Baoding scientific research and development plan (13ZG022).

\section{References}

[1] Xu Minglei, Xie Suying, Zhao Na: Stability of Weak Solution P Index of Quasilinear Elliptic Equation [J], Journal of University of Electronic Science and Technology of China, 2012 (02).

[2] Hu Yexin: Stability of Boundary Values of Quasilinear Elliptic Equation [J], Mathematical Journal (Chinese version), 2014 (11).

[3] Yang Guoying, Qi Ruigai: Discussion on Boundary Values of Quasilinear Elliptic Equation [J], Journal of Henan Polytechnic University (Natural Science), 2010 (06).

[4] Yang Jun, Shen Yaotian: Existence of Positive Solution of Quasilinear Elliptic Equation with Potential [J], Mathematica Applicata, 2011 (07).

[5] Zhao Na, Xie Suying: Uniqueness of Weak Solution of Second-order Quasilinear Elliptic Equation [J], Mathematica Applicata, 2012 (01). 